\title{
Characteristics and Outcomes of Potentially Inappropriate Admissions to the Intensive Care Unit
}

\author{
Sooim Sin, Sang-Min Lee, Jinwoo Lee \\ Division of Pulmonary and Critical Care Medicine, Department of Internal Medicine, Seoul National University Hospital, Seoul National University College of \\ Medicine, Seoul, Korea
}

Background: Admission of patients perceived as potentially inappropriate for intensive care is a very sensitive and controversial issue. We aimed to evaluate the use of medical resources in the intensive care unit (ICU) and outcomes of patients according to a physician's judgment of appropriateness.

Methods: ICU physicians classified patients who were admitted to the medical ICU of a tertiary hospital as appropriate or inappropriate for intensive care within 24 hours of admission. Patient outcomes including mortality were analyzed according to appropriateness. Additionally, the usage and duration of mechanical ventilation (MV), renal replacement therapy (RRT), and extracorporeal membrane oxygenation (ECMO) were analyzed according to appropriateness.

Results: In total, 105 patients (male, 55.4\%; mean age, 62 years) were included. Twelve (11.4\%) patients were considered inappropriate for intensive care based on guidance published by the Society of Critical Care Medicine through a questionnaire survey of physicians. There was no significant difference between patients considered inappropriate or appropriate for ICU admission regarding the use and duration of MV, RRT, and ECMO. In contrast, the ICU, in-hospital, 28-day, 90-day, and total mortality rates were significantly higher among patients with inappropriate admission than among patients with appropriate admission (ICU mortality: $50.0 \%$ vs. $25.8 \%, P=0.008$; in-hospital mortality: $58.3 \%$ vs. $43.0 \%, P=0.028$; 28 -day mortality: $58.3 \%$ vs. $33.3 \%, \mathrm{P}=0.019 ; 90$-day mortality: $66.7 \%$ vs. $44.1 \%, \mathrm{P}=0.023$ ).

Conclusions: Despite higher mortality, the amount of medical resources used for patients considered potentially inappropriate for intensive care did not differ from the resources used for patients considered suitable for ICU care.

Key Words: critical care; health resources; intensive care units; medical futility; mortality

\section{INTRODUCTION}

Limited health care resources should be allocated to appropriate patients, especially in critical care medicine. Despite the acknowledgment of inappropriate care for futile patients in the intensive care unit (ICU) [1,2], substantial medical resources are provided for futile treatment in medical ICUs (MICUs) [3-5]. According to nationwide statistical data from the United States, one in five Americans receives ICU care at the end of their life [2], and a study of Canadian ICUs reported that $87 \%$ of physicians were perceived to provide futile care [6].

In many Asian countries, the concept of palliative care is not well established in compari-

\section{Original Article}

Received: December 4, 2018

Revised: January 29, 2019

Accepted: February 14, 2019

\section{Corresponding author}

Jinwoo Lee

Division of Pulmonary and Critical

Care Medicine, Department of Internal Medicine, Seoul National University Hospital, Seoul National University College of Medicine, 101 Daehak-ro, Jongno-gu, Seoul 03080, Korea

Tel: +82-2-2072-7593

Fax: +82-2-763-0651

E-mail: realrain7@gmail.com

Copyright () 2019 The Korean Society of Critical Care Medicine

This is an Open Access article distributed under the terms of Creative Attributions Non-Commercial License (http:// creativecommons.org/li-censes/by-nc/4.0/) which permits unrestricted noncommercial use, distribution, and reproduction in any medium, provided the original work is properly cited. 
son with Western countries, and the traditional value of responsibility toward aging family members is very strong. The choice to receive intensive care is often made by family members and not by the patient [7]. Therefore, physicians feel that decisions of futility and withholding or withdrawal of life-sustaining care in the ICU are often difficult. According to a largescale study including many countries in Asia, over $80 \%$ of ICU physicians withhold further active therapy for futile patients, while only about $10 \%$ withdraw active therapy in South Korea, indicating that Korean ICU physicians tend to be more aggressive than those in other Asian counties $[8,9]$.

Futile treatment in the ICU is closely related to patient age [5]. South Korea officially became an aged society in 2017; people older than 65 years exceeded $14 \%$ of the total population. Moreover, Korea has been aging the fastest worldwide; if this trend continues, we can expect to become a super-aged society by 2025 [10]. This increase in the aging population will require more critical care and more potentially inappropriate treatment in the ICU that will be a major social problem in Korea.

An act on hospice and palliative care and decisions regarding life-sustaining treatment for patients at the end of life has been in effect in South Korea since February 2018; since then, changes in ICU medical care have been attempted [11]. However, futile treatment is still frequently provided in the ICU in South Korea. In contrast to western countries, and there is a lack of data regarding the burden of potentially inappropriate treatment in the ICU. In the present study, we aimed to investigate the proportion of inappropriate treatment suggesting futile treatment on admission to the MICU and compare treatment outcomes according to appropriateness. Further, we evaluated the consumed medical resources for potentially futile ICU care.

\section{MATERIALS AND METHODS}

\section{Study Design and Data Collection}

This prospective observational study was conducted at a single 12-bed MICU over a 10-month period (July 2017 to April 2018) in Seoul National University Hospital. Two intensivists, two physicians training undergoing pulmonary and critical care fellowship, and three residents were working in the unit. Each patient was cared for by one physician on fellowship and one attending resident. Patients admitted to the MICU during the study period who agreed to offer their demographics, treatment contents, and prognosis were included. Patients aged $\leq 20$ years and those whose ICU stay lasted $<24$ hours were

\section{KEY MESSAGES}

- About $10 \%$ of patients admitted to the medical intensive care unit (ICU) were considered as potentially inappropriate for ICU care.

- Despite higher mortality, the amount of medical resources used for patients considered as potentially inappropriate for intensive care did not differ from the resources used for patients considered appropriate for ICU care.

excluded. All patients and their family included in the study provided informed consent. This study was approved by the Institutional Review Board of the Seoul National University Hospital (IRB No. 1704-140-848) and conformed to the tenets of the Declaration of Helsinki. Baseline demographics of each patient including age, sex, weight, height, previous performance status, reason for admission, source of admission, Acute Physiology and Chronic Health Evaluation II (APACHE II), Sequential Organ Failure Assessment (SOFA), and Simplified Acute Physiology Score II (SAPS II) score at admission were recorded.

Inappropriate interventions in the ICU were defined based on a policy statement from the Society of Critical Care Medicine published in 2016. The policy statement defined ICU interventions as generally considered inappropriate when there is no expectation that the patient will improve sufficiently to survive outside the ICU, or when the patient's neurologic function is not expected to improve sufficiently to recognize the benefits of treatment [12]. At the beginning of every month, physicians and residents were educated on and reviewed the policy.

The two doctors assigned to each patient completed a simple questionnaire asking whether the patient was receiving appropriate treatment or inappropriate treatment within 24 hours from admission to the ICU (Supplementary Figure 1). Based on the questionnaire, patients were categorized into two groups: patients perceived to be receiving appropriate ICU treatment and patients perceived to be receiving inappropriate ICU treatment (patients perceived to be probably inappropriate or inappropriate in the questionnaire were designated to the group of patients perceived to be receiving inappropriate ICU treatment). Patients were categorized as inappropriate when more than one doctor assessed them as such. Length of stay in the ICU and hospital, treatment during ICU stay, blood transfusions, mortality, and other adverse outcomes during ICU stay were obtained for each patient. 


\section{Statistical Analysis}

Student t-test and Mann-Whitney U-test were used for betweengroup comparisons of demographics involving continuous variables, and the chi-square test and Fisher exact test were used for those involving categorical variables. Kaplan-Meier analysis was performed with a log-rank test to compare mortality according to the main group or subgroup. The P-values

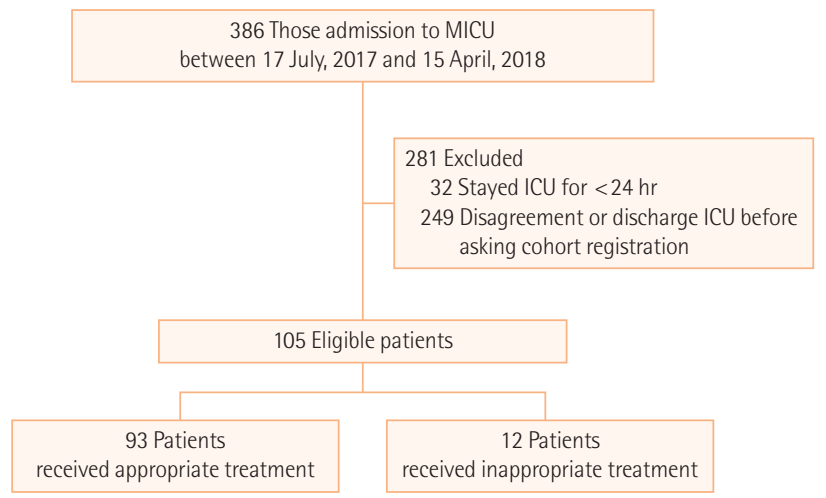

Figure 1. Flow diagram of study population. MICU: medical intensive care unit. less than 0.05 were considered statistically significant. Data analyses were conducted using STATA ver. 13 (Stata Corp., College Station, TX, USA).

\section{RESULTS}

\section{Patient Enrollment and Baseline Characteristics}

During the 10-month study period, 386 patients were admitted to the MICU; among these, 32 patients stayed in the ICU for $<24$ hours and 249 patients did not provide informed consent due to refusal to enroll or discharge from ICU before being asked to register. Therefore, 105 patients were included in the study. Of these, 12 patients (11.4\%) were judged to be inappropriate by the assigned physicians (Figure 1). The common reasons why physicians perceived these patients as inappropriate for ICU care were that their care was not cost-effective (44\%), patients experienced unnecessary pain (44\%), poor quality of life after ICU care (38\%), and need for end-of-life care (13\%) (multiple choices were available). The common reasons why physicians perceived patients as having received inappropriate ICU care were lack of adequate communication

Table 1. Baseline characteristics of enrolled patients

\begin{tabular}{|c|c|c|c|c|}
\hline Variable & Total & Appropriate treatment & Inappropriate treatment & P-value \\
\hline No. of patients & 105 & $93(88.6)$ & $12(11.4)$ & - \\
\hline Age (yr) & $62 \pm 16.0$ & $62 \pm 16.0$ & $67 \pm 15.9$ & 0.329 \\
\hline BMI $\left(\mathrm{kg} / \mathrm{m}^{2}\right)$ & $23 \pm 4.3$ & $23 \pm 4.3$ & $22 \pm 3.7$ & 0.372 \\
\hline Male sex & $57(55.4)$ & $51(54.8)$ & $7(58.3)$ & 1.000 \\
\hline Baseline performance & & & & 0.549 \\
\hline ECOG 0 & $1(1.0)$ & $1(1.1)$ & 0 & \\
\hline ECOG 1 & $5(5.0)$ & $4(4.3)$ & $1(8.3)$ & \\
\hline ECOG 2 & $14(12.9)$ & $14(15.2)$ & 0 & \\
\hline ECOG 3 & $34(33.7)$ & $30(32.6)$ & $5(41.7)$ & \\
\hline ECOG 4 & $49(45.5)$ & $43(46.8)$ & $6(50.0)$ & \\
\hline Admission route & & & & 0.157 \\
\hline$E R$ & $25(24.8)$ & $24(25.8)$ & $1(8.3)$ & \\
\hline GW & $45(44.6)$ & $40(43.0)$ & $5(41.7)$ & \\
\hline Stepdown unit ${ }^{a}$ & $5(5.0)$ & $3(3.2)$ & $2(16.7)$ & \\
\hline Others $^{b}$ & $29(25.7)$ & $26(28.0)$ & 4 (33.3) & \\
\hline APACHE II score & $19 \pm 7.5$ & $19 \pm 7.3$ & $25 \pm 7.1$ & 0.006 \\
\hline SOFA score & $8 \pm 4.1$ & $8.2 \pm 4.2$ & $9.2 \pm 3.5$ & 0.419 \\
\hline SAPS score & $46 \pm 18.1$ & $46 \pm 18.6$ & $51 \pm 15.9$ & 0.401 \\
\hline
\end{tabular}

Values are presented as mean \pm standard deviation or number (\%).

BMI: body mass index; ECOG: Eastern Cooperative Oncology Group; ER: emergency room; GW: general ward; APACHE: Acute Physiology and Chronic Health Evaluation; SOFA: Sequential Organ Failure Assessment; SAPS: Simplified Acute Physiology Score.

${ }^{a}$ Stepdown unit includes sub-intensive care unit and cardio care unit; ${ }^{b}$ Others include other hospitals, surgical intensive care unit, respiratory intensive care unit, and emergency intensive care unit. 

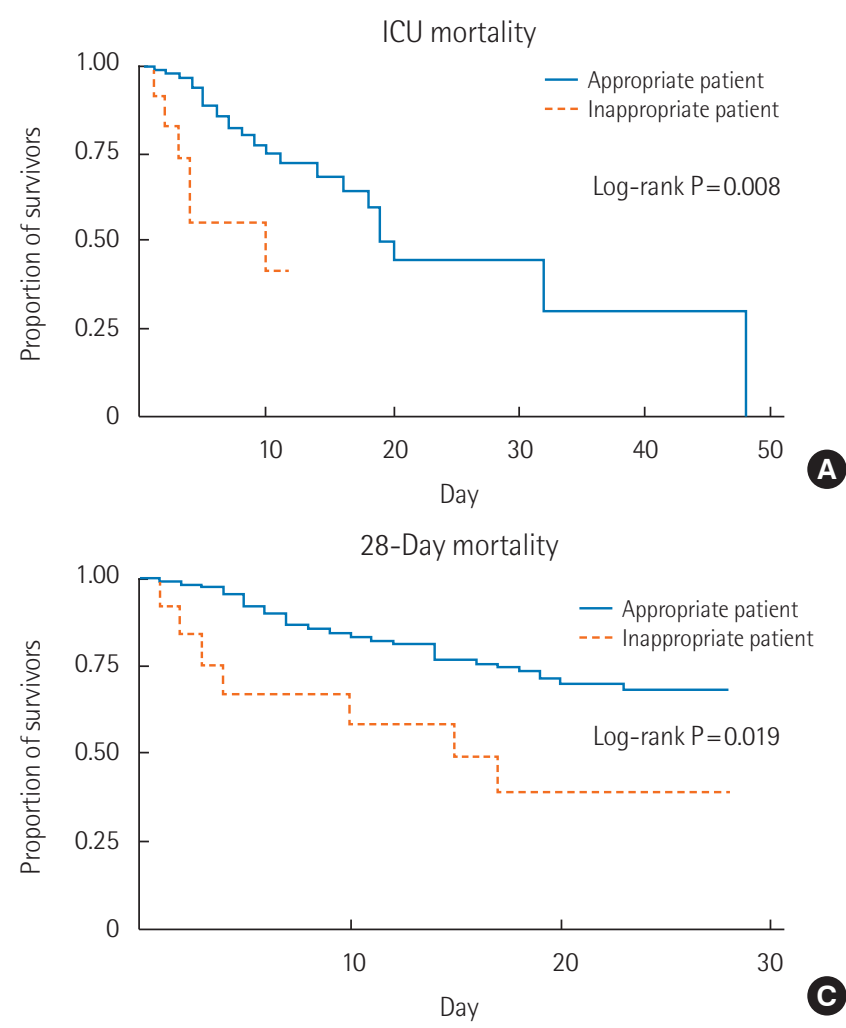

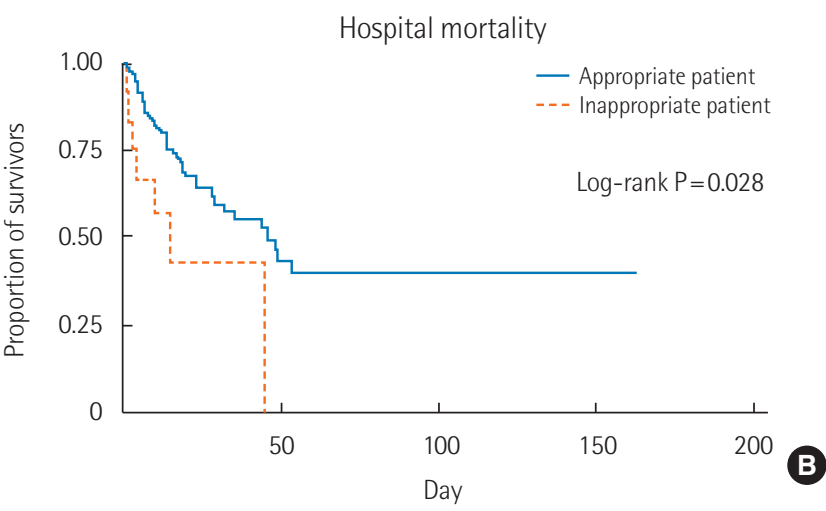

90-Day mortality

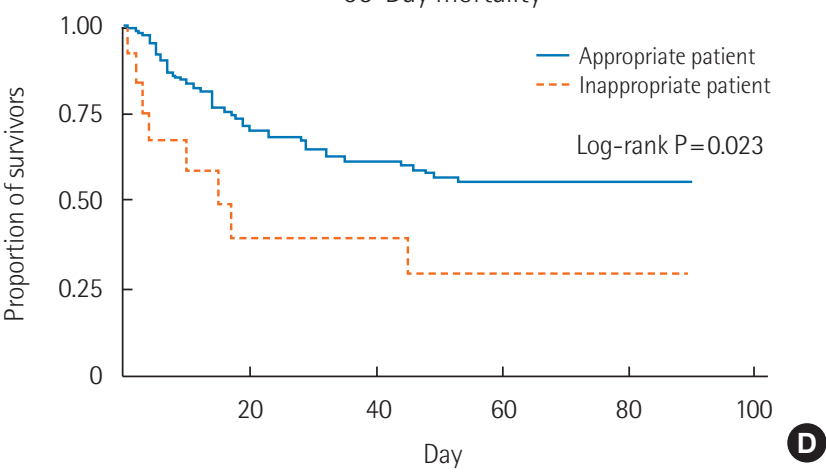

Figure 2. Survival analysis of patients in appropriate and potentially inappropriate treatment groups. (A) ICU mortality, (B) hospital mortality, (C) 28-day mortality, (D) 90-day mortality according to appropriateness of patients. ICU: intensive care unit.

with caregivers (50\%) and discrepancies between medical staff opinions (50\%) (multiple choices were available) (Supplementary Figure 2).

The mean age of included patients was 62 years, and $55.4 \%$ of patients were male (Table 1). The mean age of patients perceived to be inappropriate was higher than that of patients perceived to be appropriate, but this difference was not statistically significant. Only the APACHE II score at admission was significantly higher in patients perceived to be inappropriate than in patients perceived to be appropriate. Otherwise, there were no differences in SOFA score and SAPS (Table 1).

\section{ICU Outcomes}

Among patients considered to be inappropriate and appropriate, ICU mortality was $50.0 \%$ and $25.8 \%(\mathrm{P}=0.008)$, in-hospital mortality was $58.3 \%$ and $43.0 \%(\mathrm{P}=0.028)$, 28-day mortality was $58.3 \%$ and $33.3 \%(\mathrm{P}=0.019)$, and 90 -day mortality was $66.7 \%$ and $44.1 \%(\mathrm{P}=0.023)$, respectively. As expected, the ICU, hospital, 28-day, and 90-day mortality were significantly higher for patients perceived to be inappropriate than patients perceived to be appropriate (Figure 2). There was no significant difference between the two groups regarding ICU length
Table 2. Treatment outcomes and medical resources consumed in ICU

\begin{tabular}{lccc}
\hline Variable & $\begin{array}{c}\text { Appropriate } \\
\text { treatment }\end{array}$ & $\begin{array}{c}\text { Inappropriate } \\
\text { treatment }\end{array}$ & P-value \\
\hline No. of patients & $93(88.6)$ & $12(11.4)$ & - \\
MV & $63(67.7)$ & $6(50.0)$ & 0.332 \\
Duration of MV (day) ${ }^{\mathrm{a}}$ & $4(0-378)$ & $4(1-11)$ & 0.860 \\
Prone position & $6(6.5)$ & 0 & 1.000 \\
ECMO & $4(4.3)$ & $2(16.7)$ & 0.139 \\
Duration of ECMO (day) $^{\mathrm{a}}$ & $6(1-46)$ & $7(2-11)$ & 0.800 \\
Tracheostomy & $15(16.3)$ & $1(8.3)$ & 0.687 \\
Central line insertion & $34(36.6)$ & $5(41.7)$ & 0.758 \\
RRT & $31(33.3)$ & $7(58.3)$ & 0.114 \\
Duration of RRT (day) $^{\mathrm{a}}$ & $5(1-23)$ & $4(1-11)$ & 0.854 \\
ICU LOS (day) $^{b}$ & $7.0(3.5-1.0)$ & $4.5(2.3-10.8)$ & 0.330 \\
Hospital LOS (day) $^{b}$ & $19.0(11.5-37.0)$ & $10.5(3.3-19.5)$ & 0.020 \\
\hline
\end{tabular}

Values are presented as number (\%) unless otherwise indicated. ICU: intensive care unit; MV: mechanical ventilation; ECMO: extracorporeal membrane oxygenation; RRT: renal replacement therapy; LOS: length of stay.

a'Median (range), Mann-Whitney U-test; ${ }^{b}$ Median (interquartile range), Mann-Whitney U-test. 
Table 3. Adverse events during intensive care unit stay

\begin{tabular}{lccc}
\hline Variable & $\begin{array}{c}\text { Appropriate } \\
\text { treatment }\end{array}$ & $\begin{array}{c}\text { Inappropriate } \\
\text { treatment }\end{array}$ & P-value \\
\hline No. of patients & $93(88.6)$ & $12(11.4)$ & - \\
Hypoxic brain injury & $4(4.3)$ & $2(16.7)$ & 0.139 \\
VAP & $3(3.2)$ & 0 & $>0.999$ \\
Sepsis & $23(24.7)$ & $3(25.0)$ & $>0.999$ \\
ARDS & $18(19.4)$ & $1(8.3)$ & 0.690 \\
CPR & $5(5.3)$ & $2(16.7)$ & 0.182 \\
\hline
\end{tabular}

Values are presented as number (\%). Two tailed Fisher exact test was conducted.

VAP: ventilator associated pneumonia; ARDS: acute respiratory distress syndrome; CPR: cardiopulmonary resuscitation.

of stay. Hospital length of stay was significantly shorter with patients perceived to be inappropriate than patients perceived to be appropriate (Table 2); however, there was no significant difference between the groups among survivors (36.4 days in the appropriate group vs. 19.4 days in the inappropriate group, $\mathrm{P}=0.217$ ). The incidence of adverse events such as hypoxic brain injury, ventilator-associated pneumonia, sepsis, acute respiratory distress syndrome, and cardiopulmonary resuscitation yielded no differences between groups (Table 3 ).

\section{Medical Resource Utilization}

Among patients considered to be appropriate and inappropriate, the proportion of patients who received mechanical ventilation was $67.7 \%$ and $50 \%$, renal replacement therapy (RRT) was $33.3 \%$ and $58.3 \%$, and extracorporeal membrane oxygenation (ECMO) was $4.3 \%$ and $16.7 \%$, respectively. There were no significant differences in the proportion of patients who received each treatment (Table 2).

In addition, the amount of blood products administered to patients was analyzed. Of 93 (88.6\% of total patients) patients who were perceived to be appropriate, 62 patients $(66.7 \%)$ received at least one unit of blood during ICU care; transfused products were comprised of 353 units of packed red blood cells (PRBC; 90.1\% of PRBC transfused into all patients) and 326 (88.8\%) units of plateletpheresis. All 12 (11.4\% of total patients) patients who were assessed to be inappropriate received at least one unit of blood products during ICU care, including 39 units of packed red blood cells (9.9\% of PRBC transfused into all patients) and 41 (11.2\%) units of plateletpheresis.

\section{DISCUSSION}

The principal finding of the current study is that patients per- ceived to be inappropriate at ICU admission showed significantly higher mortality risk despite equivalent medical resources consumed compared with patients perceived to be appropriate. Mortality was significantly higher in patients considered to be inappropriate than in patients perceived to be appropriate at every point, including ICU, hospital, 28 day, and 90 day mortality.

The proportion of inappropriate patients in this study was $11.4 \%$ of all included patients, in line with the proportion of several studies conducted in the United States and Europe that reported $10.4 \%$ and $14 \%$ of patients as futile, respectively $[13,14]$. However, studies conducted in the United States including over 1,000 patients reported that $11 \%$ of patients were perceived by physicians as receiving futile treatment and $8.6 \%$ were perceived as receiving probably futile treatment, which is higher than our study $[1,4,5]$. Another study in the United States reported $20.9 \%$ of patients were perceived by physicians as receiving futile treatment, which is also a higher proportion than the current study [15]. This likely results from differences in attitudes regarding appropriate treatment between physicians in South Korea and Western countries. Like other East Asian countries, in South Korea, Confucianism and familycentered decisions are major obstacles to decision making regarding futility in the ICU [16-18], although there have been gradual changes in our culture.

There is a lack of data comparing ICU outcomes between patients considered inappropriate and appropriate. Joynt et al. [19] reported the relative risk of hospital mortality for patients considered futile as 2.47 (95\% confidence interval, 2.12 to 2.86). In contrast to our study, the futility of patients was assessed ahead of admission to the ICU and admission was refused for those assessed as futile. Huynh et al. [5] showed significantly higher hospital and 6-month mortality rates among patients considered inappropriate than among patients considered appropriate using chi-square analysis. In our study, the judgment of appropriateness was made within 24 hours of ICU admission, and therefore the judgment did not affect the decision to admit a patient to the ICU.

Although there was no significant difference between patient groups regarding consumption of medical resources, such as application proportion and duration of mechanical ventilation, ECMO, and RRT, there was a significant difference in mortality between the groups. Furthermore, blood products, which are donated resources with high value, were also provided in almost equal proportions. This represents an inefficient use of limited medical resources and can be considered unethical if the care of patients expected to recover is in- 
terrupted due to futile treatment for patients not expected to recover.

There are several limitations to the present study. This study was conducted in a single tertiary center, and it may be difficult to generalize results to the general population. However, this is the first study in South Korea to investigate potentially inappropriate treatment in the ICU, and it may be a foundation for future large multi-center, multi-national studies. Also, different physicians evaluated the appropriateness every month. Therefore, there may be a lack of consistency in physician evaluations. However, there was no significant difference in the overall proportion of inappropriate patients compared with other studies, and we were able to assess the opinion of various physicians. Finally, it is possible that patients in the potentially inappropriate group received less aggressive treatment compared with those considered appropriate. However, the aggressiveness of treatment is not likely to differ between groups considering that there are no differences in the usage of medical resources.

In the present study, patients considered inappropriate for critical care accounted for one out of 10 patients admitted to the MICU. Although similar amounts of medical resources were consumed for both inappropriate and appropriate patients, significantly higher mortality was observed in the potentially inappropriate group of patients. Based on these data, the need for perceptional change regarding decisions to receive or provide intensive care should be recognized. The ICU triage decisions of intensivists need to be respected for appropriate allocation of limited medical resources. This will result in a healthcare environment in which patients who truly require critical care medicine can be properly cared for.

\section{CONFLICT OF INTEREST}

No potential conflict of interest relevant to this article was reported.

\section{ORCID}

Sooim Sin https://orcid.org/0000-0002-4468-311X

Sang-Min Lee https://orcid.org/0000-0002-1388-9318

Jinwoo Lee https://orcid.org/0000-0003-0958-106X

\section{AUTHOR CONTRIBUTIONS}

Conceptualization: JL. Data curation: SS, SML. Formal analysis: SS. Methodology: JL, SS. Project administration: JL. Visu- alization: SS. Writing - original draft: SS, JL. Writing - review \& editing: SML, JL.

\section{SUPPLEMENTARY MATERIALS}

The online-only supplement data are available with this article online: https://doi.org/10.4266/acc.2018.00388

\section{REFERENCES}

1. Huynh TN, Kleerup EC, Raj PP, Wenger NS. The opportunity cost of futile treatment in the ICU. Crit Care Med 2014;42:197782.

2. Angus DC, Barnato AE, Linde-Zwirble WT, Weissfeld LA, Watson RS, Rickert T, et al. Use of intensive care at the end of life in the United States: an epidemiologic study. Crit Care Med 2004;32:638-43.

3. Riley GF, Lubitz JD. Long-term trends in Medicare payments in the last year of life. Health Serv Res 2010;45:565-76.

4. Neville TH, Ziman A, Wenger NS. Blood products provided to patients receiving futile critical care. J Hosp Med 2017;12:73942.

5. Huynh TN, Kleerup EC, Wiley JF, Savitsky TD, Guse D, Garber $\mathrm{BJ}$, et al. The frequency and cost of treatment perceived to be futile in critical care. JAMA Intern Med 2013;173:1887-94.

6. Palda VA, Bowman KW, McLean RF, Chapman MG. "Futile" care: do we provide it? Why? A semistructured, Canada-wide survey of intensive care unit doctors and nurses. J Crit Care 2005;20:207-13.

7. Kim J, Choi SM, Park YS, Lee CH, Lee SM, Yim JJ, et al. Factors influencing the initiation of intensive care in elderly patients and their families: a retrospective cohort study. Palliat Med 2016;30:789-99

8. Phua J, Joynt GM, Nishimura M, Deng Y, Myatra SN, Chan YH, et al. Withholding and withdrawal of life-sustaining treatments in intensive care units in Asia. JAMA Intern Med 2015;175:36371.

9. Lee SJ, Kim HY. Experience of life-sustaining treatment in patient care among intensive care unit nurses: phenomenological approach. J Korean Acad Fundam Nurs 2016;23:172-83.

10. Ministry of the Interior and Safety. Resident registration statistics. Seoul: Ministry of the Interior and Safety; 2018.

11. Korean act on hospice-palliative care and life-sustaining treatment decision-making, Act No. 14013 (February 3, 2016).

12. Kon AA, Shepard EK, Sederstrom NO, Swoboda SM, Marshall MF, Birriel B, et al. Defining futile and potentially inappropriate interventions: a policy statement from the Society of Criti- 
cal Care Medicine Ethics Committee. Crit Care Med 2016;44: 1769-74.

13. Neville TH, Wiley JF, Yamamoto MC, Flitcraft M, Anderson B, Curtis JR, et al. Concordance of nurses and physicians on whether critical care patients are receiving futile treatment. Am J Crit Care 2015;24:403-10.

14. Garrouste-Orgeas M, Montuclard L, Timsit JF, Misset B, Christias M, Carlet J. Triaging patients to the ICU: a pilot study of factors influencing admission decisions and patient outcomes. Intensive Care Med 2003;29:774-81.

15. Chang DW, Dacosta D, Shapiro MF. Priority levels in medical intensive care at an academic public hospital. JAMA Intern Med 2017;177:280-1.
16. Makino J, Fujitani S, Twohig B, Krasnica S, Oropello J. End-oflife considerations in the ICU in Japan: ethical and legal perspectives. J Intensive Care 2014;2:9.

17. Koh Y. Current status of end-of-life care in Korean hospitals. J Korean Med Assoc 2012;55:1171-7.

18. Ho A, Tsai DF. Making good death more accessible: end-of-life care in the intensive care unit. Intensive Care Med 2016;42: 1258-60.

19. Joynt GM, Gomersall CD, Tan P, Lee A, Cheng CA, Wong EL. Prospective evaluation of patients refused admission to an intensive care unit: triage, futility and outcome. Intensive Care Med 2001;27:1459-65. 
The following are questionnaires for ICU cohort study. Thank you for your answer.

1. What is your position?

$\square$ Professor

$\square$ Fellow

$\square$ Resident

2. Do you think it is appropriate for this patient to be treated in the ICU?

$\square$ Appropriate

$\square$ Probably inappropriate

$\square$ Inappropriate

Please continue following if you have chosen "Probably inappropriate" or "Inappropriate".

3. Please choose all of the reasons why you think this patient is (probably) inadequate to be treated in the ICU.

$\square$ This patient needs end-of-life care.

$\square$ The quality of life after the ICU treatment will be poor.

$\square$ This is not a cost-effective treatment considering limited medical resources.

$\square$ It will cause unnecessary pain for the patient.

$\square$ Others (please specify)

4. What is the reason do you think for this patient to receive (probably) inadequate treatment?

$\square$ Guardian's request

$\square$ Lack of communication

$\square$ Discrepancies between opinions of medical staffs

$\square$ Others (please specify)

Supplementary Figure 1. Questionnaire for assessment of inappropriateness and reasons of inappropriateness. ICU: intensive care unit. 
Reasons why the physicians perceived those patients as inappropriate

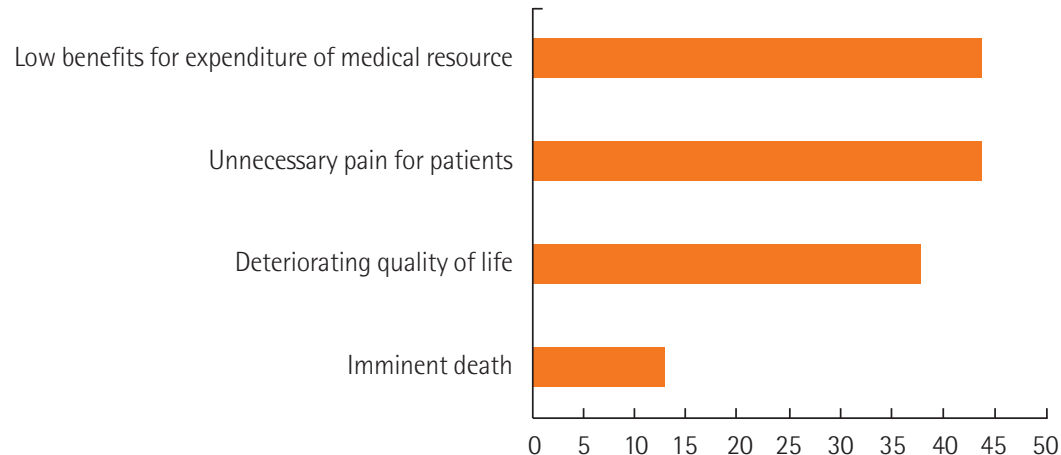

Reasons why the physicians perceived those patients as having received inappropriate ICU care

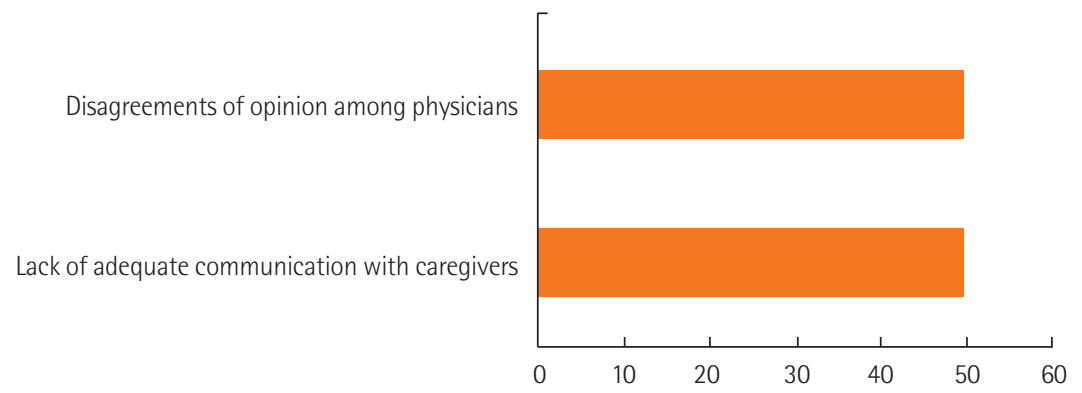

Supplementary Figure 2. Results of questionnaire. ICU: intensive care unit. 